\title{
Dominance is necessary to explain human status hierarchies
}

\author{
Joey T. Cheng ${ }^{\mathrm{a}, 1}$, Jessica L. Tracy ${ }^{\mathrm{b}}$, and Joseph Henrich ${ }^{\mathrm{c}}$ \\ aDepartment of Psychology, York University \\ ${ }^{\mathrm{b}}$ Department of Psychology, University of British Columbia \\ ${ }^{\mathrm{c}}$ Department of Human Evolutionary Biology, Harvard University
}

${ }^{1}$ To whom correspondence should be addressed: chengjt@yorku.ca

${ }^{*}$ To view an extended version of this letter with additional details, data, and analyses, see:

https://github.com/joeytcheng/Dominance-Necessary-to-Explain-Status 
Durkee et al. (1) provide useful cross-cultural data on people's perceptions of the foundations of human status. However, at least three statistical and methodological shortcomings cast serious doubt on their conclusion that dominance contributes only weakly to status.*

First, the predictor variables included in the critical analyses suffer from severe collinearity. These models regress status (defined by terms like 'reputation') on four predictors simultaneously: benefit-generation ability (BGA), benefit-generation willingness (BGW), cost-infliction ability (CIA), and cost-infliction willingness (CIW). As Figure 1 shows, several of these predictors are so strongly intercorrelated $(r \geq$ 0.80 ) as to be largely redundant. Not only do these correlations exceed conventional cut-offs for diagnosing collinearity $(r<0.8)$ and produce variance inflation factors exceeding the 2.5 threshold believed to warrant concern (3.35 to 5.76), but our simulations confirm that they result in severely biased estimates (Tables S1-2).

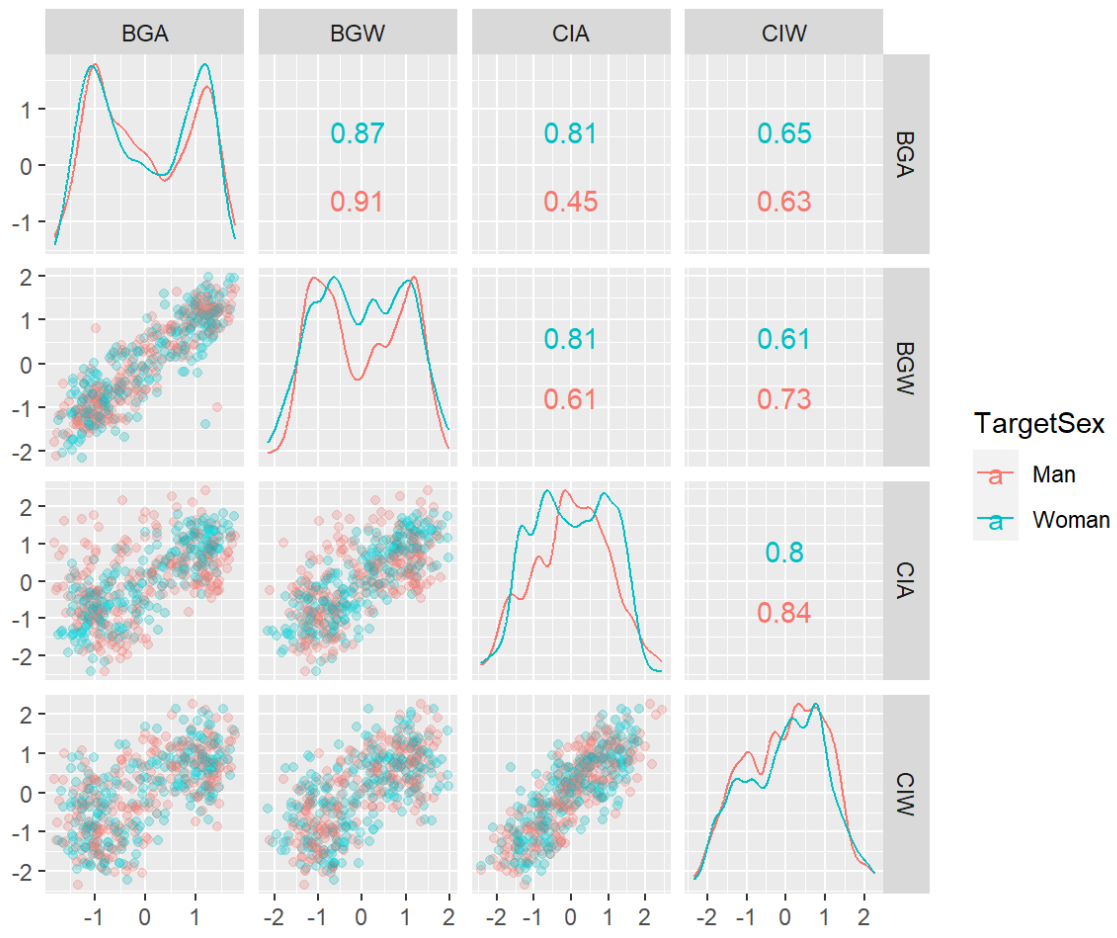

Fig. 1 | Relations among the predictors.

To address the collinearity issue in Durkee et al.'s models, we (a) combined the two benefits variables and the two costs variables into composites, and (b) entered only one predictor each for benefits and costs. These approaches, which reduce collinearity, deliver a different result: Both cost-infliction and benefitdelivery contribute significantly to perceived status impact (Tables S3-4), though benefit-delivery remains more important.

Second, although the authors claim to explain the determinants of 'status', which theoretically includes dominance, their methods are heavily biased toward capturing only prestige, a status based on freelyconferred deference. Durkee et al. asked participants about factors that influence status, as operationalized with terms that semantically cue mostly prestige (Table 1). It is therefore unsurprising that participants endorsed benefit-delivery (prestige), and not cost-infliction (dominance), as a means of attaining this kind of status. 


\begin{tabular}{|c|c|c|c|}
\hline $\begin{array}{l}\text { Sampling } \\
\text { Country }\end{array}$ & $\begin{array}{l}\text { Language } \\
\text { of Study } \\
\text { Materials }\end{array}$ & Prompt & English Translation \\
\hline Brazil & English & status and reputation & [already in English] \\
\hline China & Chinese & 地位和名誉 & status and reputation \\
\hline Colombia & Spanish & estatus (prestigio social) y la reputación & prestigious reputation \\
\hline Eritrea & English & status and reputation & [already in English] \\
\hline Estonia & Estonian & [materials missing] & [materials missing] \\
\hline Germany & German & prestige und ansehen & prestige and reputation \\
\hline Guam & English & status and reputation & [already in English] \\
\hline Japan & Japanese & [materials missing] & [materials missing] \\
\hline Korea & Korean & 명성과지위 & status and reputation \\
\hline Poland & Polish & status i reputację & status and reputation \\
\hline Romania & Romanian & apreciat de ceilalti & appreciation by others \\
\hline Russia & Russian & [materials missing] & [materials missing] \\
\hline USA & English & status and reputation & [already in English] \\
\hline Zimbabwe & Shona & chimiro & how one is viewed \\
\hline
\end{tabular}

Table 1 | Translations of prompts aimed to measure perceived status impact."

Confirming this interpretation, in two studies we found that the authors' status terms are interpreted by English speakers as synonymous with 'prestige' and other words connoting non-coercive status, but only weakly overlap with words connoting 'dominance', or with the broader concept that should underpin any definition of status: influence (Figures 2-3). It is problematic to purport to test a theory of status as derived from both prestige and dominance (2) using methods that semantically capture mostly prestige, then claim a failure to find any impact of dominance. 


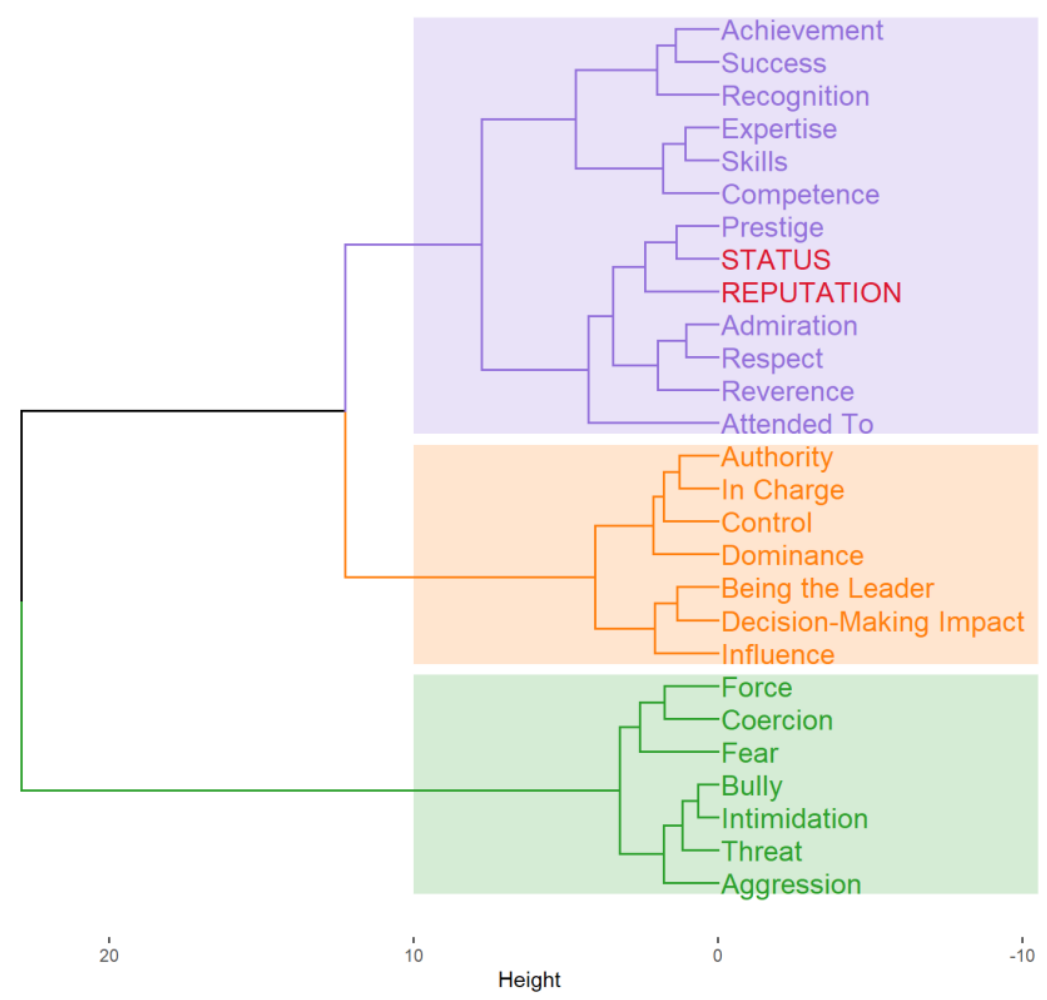

Fig. 2 | Cluster analysis: 'status' and 'reputation' are semantically similar to other prestige but not dominance terms." 


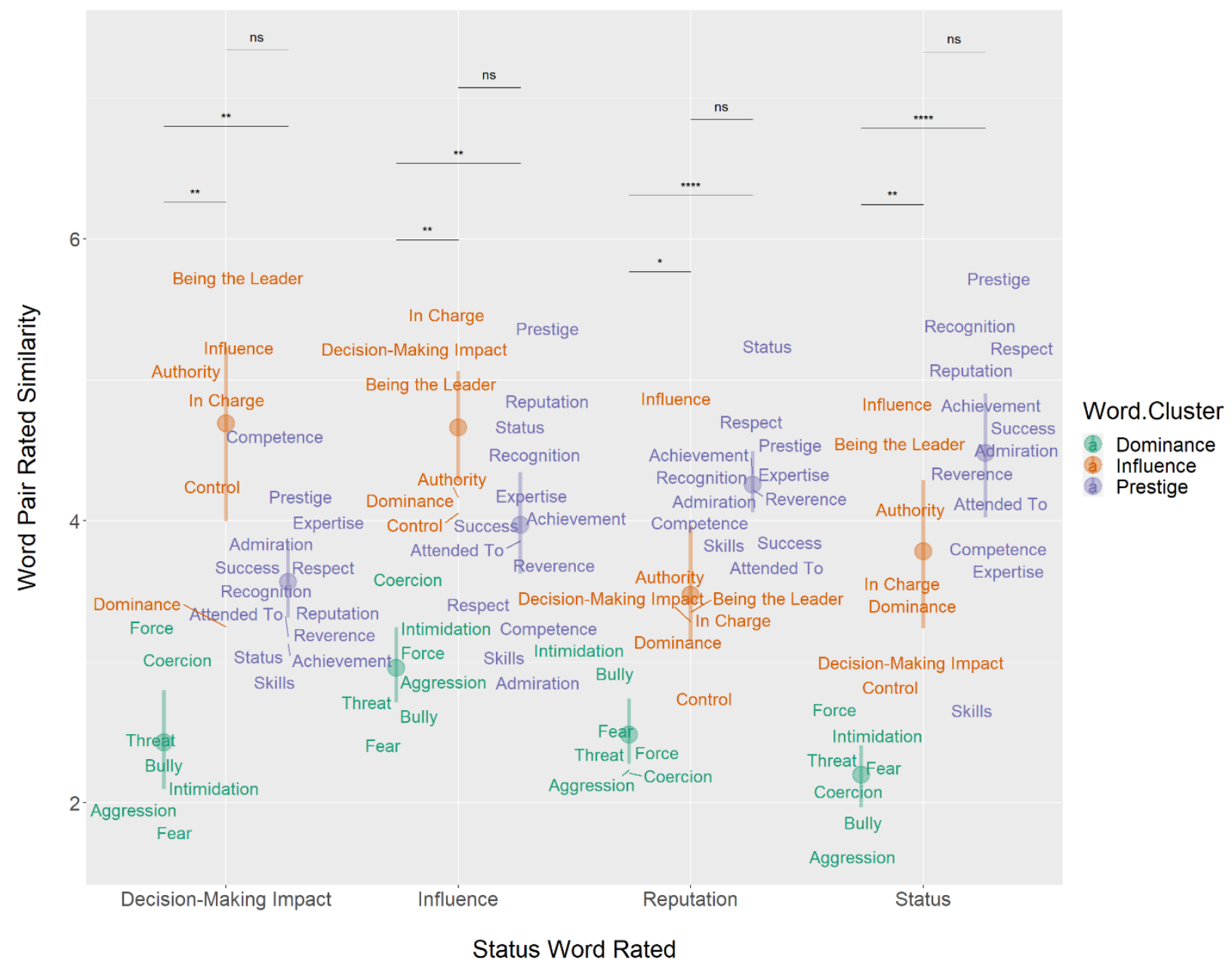

Fig. 3 | Rated similarity among status terms.*

Third, the authors' enterprise hinges on the assumption that people's subjective beliefs about what determines status can be taken as evidence for what actually determines status. Yet prior studies suggest that introspective beliefs about status do not necessarily capture reality (3-5). Furthermore, studies that have examined actual status relations within groups consistently find that both prestige and dominance contribute to status, and can have a similarly large impact (6-10).

In conclusion, Durkee et al.'s findings do not allow for clear conclusions about the foundations of human status.

\section{REFERENCES}

1. P. K. Durkee, A. W. Lukaszewski, D. M. Buss, Psychological foundations of human status allocation. Proc. Natl. Acad. Sci. 117, 21235-21241 (2020).

2. J. Henrich, F. J. Gil-White, The evolution of prestige: Freely conferred deference as a mechanism for enhancing the benefits of cultural transmission. Evol. Hum. Behav. 22, 165-196 (2001). 
3. L. ten Brinke, D. Keltner, Theories of power: Perceived strategies for gaining and maintaining power. J. Pers. Soc. Psychol., (in press).

4. R. E. Nisbett, T. D. Wilson, Telling more than we can know: Verbal reports on mental processes. Psychol. Rev. 84, 231-259 (1977).

5. R. F. Baumeister, K. D. Vohs, D. C. Funder, Psychology as the science of self-reports and finger movements: Whatever happened to actual behavior? Perspect. Psychol. Sci. 2, 396-403 (2007).

6. Z. H. Garfield, E. H. Hagen, Investigating evolutionary models of leadership among recently settled Ethiopian hunter-gatherers. Leadersh. Q. 31, 101290 (2020).

7. C. R. von Rueden, M. Gurven, H. Kaplan, The multiple dimensions of male social status in an Amazonian society. Evol. Hum. Behav. 29, 402-415 (2008).

8. J. T. Cheng, J. L. Tracy, T. Foulsham, A. Kingstone, J. Henrich, Two ways to the top: Evidence that dominance and prestige are distinct yet viable avenues to social rank and influence. J. Pers. Soc. Psychol. 104, 103-125 (2013).

9. C. Anderson, D. L. Sharps, C. J. Soto, O. P. John, People with disagreeable personalities (selfish, combative, and manipulative) do not have an advantage in pursuing power at work. Proc. Natl. Acad. Sci. 117, 22780-22786 (2020).

10. C. O. Brand, A. Mesoudi, Prestige and dominance-based hierarchies exist in naturally occurring human groups, but are unrelated to task-specific knowledge. R. Soc. Open Sci. 6, 181621 (2019).

${ }^{*}$ See https://github.com/joeytcheng/Dominance-Necessary-to-Explain-Status for an extended discussion and more details. 